\title{
Voltage mode electronically tunable full-wave rectifier
}

\author{
Predrag B. Petrović, Milan Vesković, Slobodan Đukić *
}

\begin{abstract}
The paper presents a new realization of bipolar full-wave rectifier of input sinusoidal signals, employing one MO-CCCII (multiple output current controlled current conveyor), a zero-crossing detector (ZCD), and one resistor connected to fixed potential. The circuit provides the operating frequency up to $10 \mathrm{MHz}$ with increased linearity and precision in processing of input voltage signal, with a very low harmonic distortion. The errors related to the signal processing and errors bound were investigated and provided in the paper. The PSpice simulations are depicted and agree well with the theoretical anticipation. The maximum power consumption of the converter is approximately $2.83 \mathrm{~mW}$, at $\pm 1.2 \mathrm{~V}$ supply voltages.

K e y w ords: multiple output current-controlled current conveyor, zero-crossing detector, full-wave rectifier, bipolar
\end{abstract} transistors, harmonic distortion

\section{Introduction}

Precision rectifiers are important building blocks for signal processing, conditioning and instrumentation of low-level signals and are extensively used in wattmeters, $\mathrm{AC}$ voltmeters, $\mathrm{RF}$ demodulators, linear function generators and various nonlinear analogue signal-processing circuits [1-3]. Owing to the threshold voltage of diodes, the conventional diode rectifiers are limited and are only used in specific applications, such as DC voltage supplies. However, simple diode rectifiers cannot be used for applications requiring accuracy in the threshold voltage range, the. This can be overcome by using high precision integrated circuit rectifiers.

Although the use of current-mode (CM) active devices is restricted to current processing, it offers certain advantages such as higher usable gain, more reduced voltage excursion at sensitive nodes, greater linearity, less power consumption, wider bandwidth, better accuracy and larger dynamic range compared to that of their voltage-mode counterparts. The CCII is a reported active component, especially suitable for the class of analog signal processing. However, the CCII can not control the parasitic resistance at $x\left(R_{x}\right)$ port, so - when it is used in some circuits, it unavoidably requires certain external passive components, especially the resistors. This makes it inappropriate for IC implementation, as it occupies a greater chip area, high power dissipation and excludes electronic controllability. On the other hand, the recently introduced second-generation current controlled conveyor (CCCII) has the advantage of electronic adjustability over the CCII [4]. Also, the use of dual-output current-conveyors is found to be useful in the derivation of current-mode single input circuits.

The use of the current conveyor to improve performance of an OA-based circuit was discussed in [5]. Full- wave rectifiers based on a CMOS class $\mathrm{AB}$ amplifier and current rectifier operation are described in [6,7]. This circuit offers a wide dynamic range and shows a broadband operation. CMOS integrated active rectifier concept is an innovative approach for higher efficiencies [8]. These rectifiers provide output voltages nearly at the level of the input voltage combined with low power consumption, which was also achieved through the circuit design proposed here. In [9], a single CCCII-based precision full-wave rectifier circuit is proposed using a three-output CCCII, two MOS transistors and a resistor with large cross-over distortion for a low frequency of $5 \mathrm{KHz}$. In [10,11], full-wave rectifier circuits are proposed using two second-generation current conveyors (CCIIs) and four diodes.

In 2006, Yuce et al [12] proposed a full-wave rectifier deploying two plus-type second-generation current conveyors $(\mathrm{CCII}+\mathrm{s})$ and three n-channel metal-oxide semiconductor field-effect transistors (MOSFETs). Also, Minaei and Yuce [13] proposed a voltage-mode (VM) fullwave rectifier with high-input impedance using a dual-X second-generation current conveyor (DXCCII) and three n-channel MOSFETs in 2008. The circuits presented in $[12,13]$ require no passive components and they operate in VM. Some current-mode (CM) full-wave rectifiers have been reported in the literature [14-18]. However, the reported rectifiers usually employ at least two active elements and/or four diodes, and additional sub circuits. For example, in [15], the circuit uses two CCII+s and four diodes. The structure in [16] employs one current conveyor and one universal voltage conveyor (UVC) and two diodes. In [17], the proposed circuits employ at least two current and/or voltage conveyors as active elements and two diodes. A CM full-wave rectifier circuit employing one active element - namely current differencing transconductance amplifier (CDTA) - is reported in [18]. However, the circuit in [18] requires four diodes and one re-

\footnotetext{
* Faculty of Technical Sciences, Svetog Save 65, 32000 Čačak, Serbia, predrag.petrovic@ftn.kg.ac.rs
} 
Table 1. Comparison of the rectifiers

\begin{tabular}{ccccccc}
\hline Reference & Type of active components & $\begin{array}{c}\text { Number of } \\
\text { diodes }\end{array}$ & $\begin{array}{c}\text { Number of } \\
\text { resistors }\end{array}$ & $\begin{array}{c}\text { Auxiliary bias } \\
\text { sources }\end{array}$ & $\begin{array}{c}\text { Cascability } \\
\text { property }\end{array}$ & $\begin{array}{c}\text { Modes of } \\
\text { operation }\end{array}$ \\
\hline$[2]$ & 4 CCCIIs, 3 MOSFETs & - & - & yes & no & VM \\
{$[12]$} & 2 CCIIs, 3MOSFETs & - & - & no & no & VM \\
{$[13]$} & 1 DXCCII, 3 MOSFETs & - & - & yes & no & VM \\
{$[14]$} & 2 Opamps & 2 & 5 & no & no & VM \\
{$[15]$} & 2 CCIIs & 4 & 2 & no & no & VM \\
{$[16]$} & 1 CCIIs, 1 UVCs & 2 & - & no & yes & CM \\
{$[17]$} & 1 CCIIs, 1 UVCs & 2 & - & yes & yes & CM \\
{$[18]$} & 1 CDTAs & 4 & 1 & no & no & CM \\
{$[20]$} & 4 OTAs & - & - & yes & yes & CM \\
{$[22]$} & 1 CDTAs & 2 & 1 & no & yes & CM \\
{$[23]$} & 1 DXCCIIs & 2 & 1 & no & yes & CM \\
{$[24]$} & 1 MYC-CDTA & - & - & no & no & CM \\
\hline Proposed & 1 DOCCCIIs, ZCD & - & 1 & no & yes & VM \\
circuits & 2 MOSFETs & & & & &
\end{tabular}

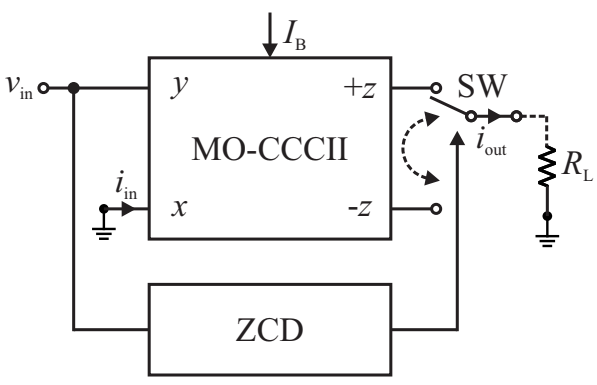

Fig. 1. The proposed circuit of the full-wave rectifier

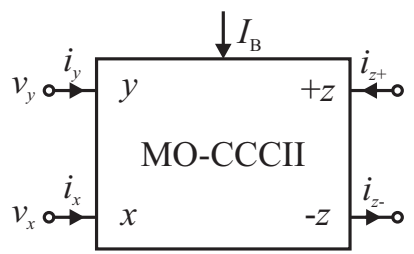

Fig. 2. Electrical symbol of MO-CCCII

sistor. Other rectifier examples can be found in [19-23]. The circuits reported in $[19,21]$ are designed based on MOS transistors. Although these circuits have fairly simple structures, the circuit in [19] requires a floating input voltage source and the circuit in [21] needs three external bias current sources which should be realised separately. The circuit in [20] employs an excessive number of OTAs as active elements and the circuits of $[22,23]$ use CDTA or DXCCII which have more complex internal structures with respect to CCII, OTA and DVCC. The circuit in [24] employs a current mode full-wave rectifier based on single modified Z-copy current difference transconductance amplifier (MZC-CDTA) and two switches.

This paper presents the principles of operation, and the detailed circuit design of the new bipolar realization of the full-wave rectifier. The features of the proposed circuit are: it employs one MO-CCCII, one zero-crossing detector, and one resistor connected to source voltage, which is suitable for fabrication in a monolithic chip. Unlike the rectifier described in $[2,3]$, which was realised using the CMOS technology, the one described in this paper involves a simpler and more accurate control structure. Besides, the proposed circuit does not require a more precise bias voltages realization and complex transistor pairing, which was typical of the realisations described in $[2,3]$. The rectifier circuit provides the operating frequency of up to $10 \mathrm{MHz}$, with increased linearity and precision in processing of input signals. The performance of the proposed circuit is illustrated by PSpice simulations, showing a good agreement with the calculation. The circuits proposed in this work have been compared to similar circuits reported in the literature. The results are depicted in Table 1.

\section{Proposed full-wave rectifier circuit}

Figure 1 presents the proposed circuit of the full-wave rectifier.

Generally, a MO-CCCII is a multiple-terminal active building block, as shown in Fig. 1. The electrical symbol of the MO-CCCII is shown in Fig. 2.

The port relations of the MO-CCCII can be presented by

$$
i_{y}=0 ; v_{x}=v_{y}+i_{x} R_{x} ; i_{z+}=+i_{x} ; i_{z-}=-i_{x} .
$$

The schematic bipolar realization is shown in Fig. 3 [25]. According to equation (1), the MO-CCCII has a unity voltage gain between terminal $\mathrm{y}$ and $\mathrm{x}$ and a unity current gain between terminal $x$ and $z$. The $R_{x}$ is an inner resistance of a translinear mixed loop $\left(\mathrm{Q}_{1}\right.$ to $\left.\mathrm{Q}_{4}\right)$ with grounded resistor equivalent controlled by bias current $I_{B}$. In this case, the parasitic resistance $R_{x}$ at the terminal $x$ can be expressed by

$$
R_{x}=\frac{V_{T}}{2 I_{B}}
$$




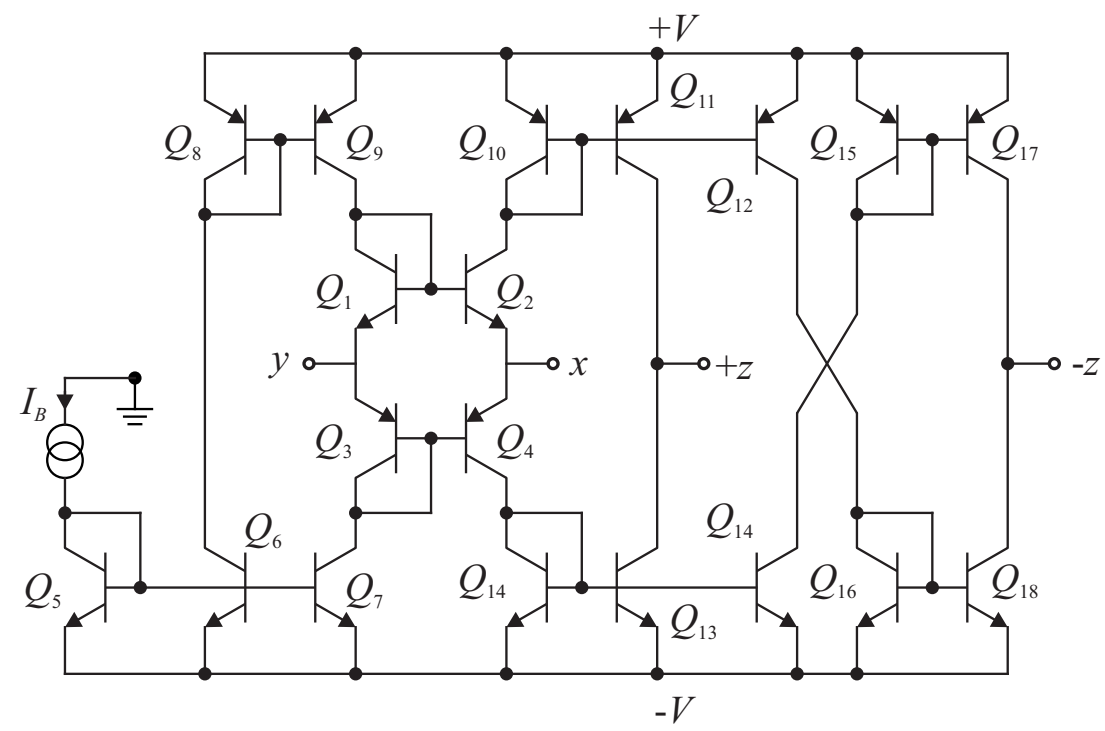

Fig. 3. Bipolar realization of MO-CCCII

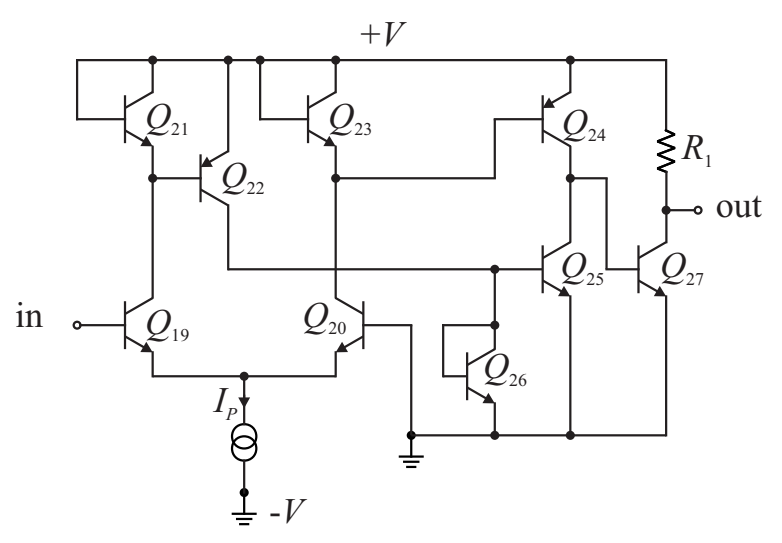

Fig. 4. Bipolar realization of comparator

where $V_{T}=26 \mathrm{mV}$ at $27^{\circ} \mathrm{C}$ is the usual thermal voltage given by $k T / q, k=$ Boltzmann's constant $=1.38 \times$ $10^{-23} \mathrm{~J} / \mathrm{K}, \mathrm{T}=$ the absolute temperature (in Kelvin's), and $q=1.6 \times 10^{-19} \mathrm{C}$ and $I_{B}$ (Fig. 1) is the bias current of the conveyor which remains tunable over several decades.

Precision in processing of the input voltage signal is directly dependent on the manner in which $\mathrm{ZCD}$ is able to reliably detect the moment when the input signal changes the polarity. This required the construction of new bipolar detector circuits, as shown in Fig. 4. The transistors $\mathrm{Q}_{19}$ and $\mathrm{Q}_{20}$ will promptly follow the variations in input voltage, thus reducing the total delay time of the comparator. The resistor $R_{1}$ has one end attached to the source from which it is powered together with the detectors. The resistor can be coupled to the source of the different voltage level, if this should prove necessary due to the demands of analog switches-two complementary MOS transistors.

By the routine analysis of the proposed full-wave circuit shown in Fig. 1 and using the properties of MOCCCII, for $v_{\text {in }}>0$, the $z+\operatorname{current}\left(v_{\text {in }} / R_{x}\right)$ to pass on to the load. For $v_{\text {in }}<0, z-$ current $\left(-v i n / R_{x}\right)$ passes on to the load, thus inverting the negative cycle of input

$$
i_{\text {out }}= \begin{cases}i_{z+}=\frac{v_{\text {in }}}{R_{x}}, & v_{\text {in }}(t) \geq 0, \\ i_{z-}=-\frac{v_{\text {in }}}{R_{x}}, & v_{\text {in }}(t) \prec 0 .\end{cases}
$$

Unidirectional current flows through the load in either case, resulting in a full-wave rectified output.

Depending on the detected sign of the input signal (practically by detecting the negative half-period of input processing signal), over the ZCD (Fig. 1), the position of the switch SW (two complementary MOS transistors) can be determined. The control voltage signal, obtained on the output of the ZCD, defines the position of the switch SW and brings the current either from port $z+$, or from port $z-$ of the MO-CCCII. Such control enables the current input from the port $z+$ on the load at the interval at which the input voltage signal is positive, ie from the port $z$ - when the input voltage is negative. The output voltage $v_{\text {out }}$ for input $v_{\text {in }}$ is

$$
v_{\text {out }}=\left\{\begin{array}{cc}
\frac{R_{L}}{R_{\text {in }}} v_{\text {in }}, & v_{\text {in }} \geq 0, \\
-\frac{R_{L}}{R_{\text {in }}} v_{\text {in }}, & v_{\text {in }}<0 .
\end{array}\right.
$$

where $R_{\text {in }}=R_{x}$. The equation (4) we can present in form

$$
v_{\text {out }}=\frac{R_{L}}{R_{\text {in }}}\left|v_{\text {in }}\right|
$$

Based on (5), it is obvious that the voltage value at the output of the proposed circuit corresponds to the rectified value of the input sinusoid signal with amplification or rectifier with attenuation. In the proposed circuit, rectification is not performed by diodes, which implies fewer ripples, compared with the known diode rectifier circuits [14-18]. It is also possible to perform low-voltage (below threshold level of the diode) rectification using the proposed circuit. 

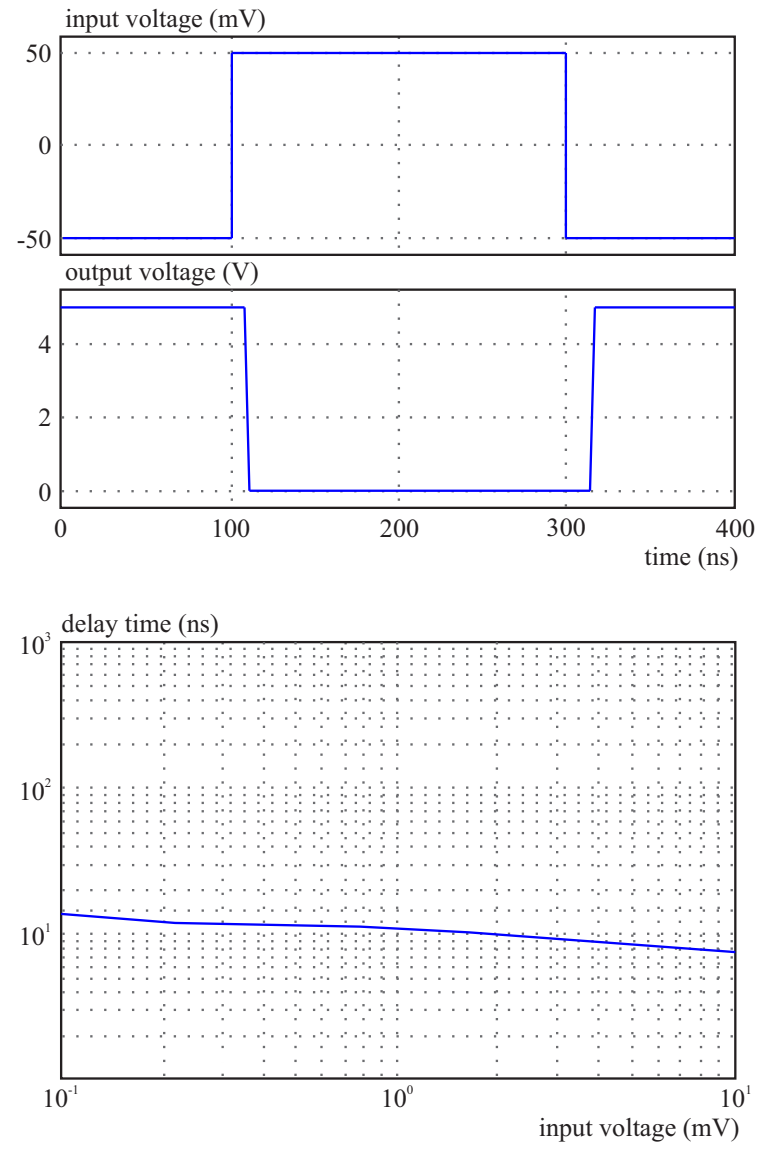

Fig. 5. (a) - Output voltage waveforms for proposed ZCD, (b) Average delays time against input voltage

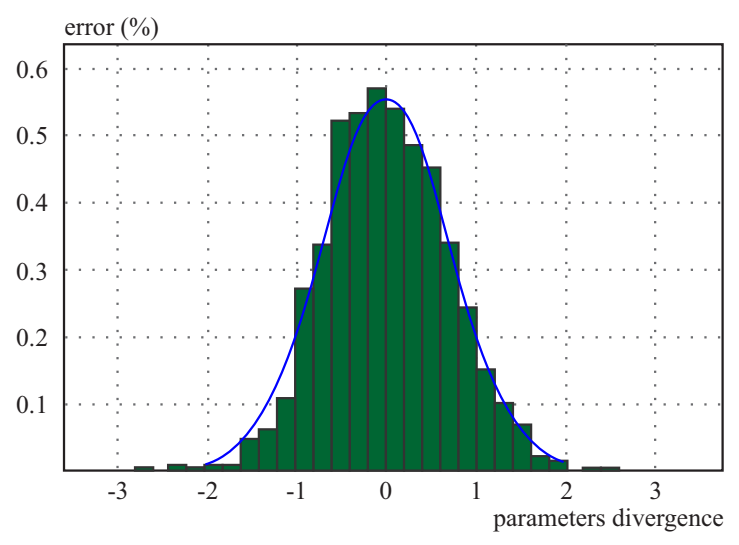

Fig. 6. The distribution of errors, for the divergence in the value of the parameters, from their nominal values

\section{Non-ideal effects}

The effects of MO-CCCII and comparator non-idealities on the full-wave rectifier performance are to be considered in this section. By considering the non-ideal MO-CCCII characteristics, (1) can be rewritten as

$$
i_{y}=0, v_{x}=\alpha v_{y}+i_{x} R_{x}, i_{z+}=+\beta_{p} i_{x}, i_{z-}=-\beta_{n} i_{x}
$$

where $\alpha=1-\varepsilon_{v}$ and $\varepsilon_{v}\left(\left|\varepsilon_{v}\right| \ll 1\right)$ represents the voltage tracking error from $y$ to $x$ terminal, $\beta_{p}=1-\varepsilon_{p}$ and $\varepsilon_{p}$ $\left(\left|\varepsilon_{p}\right| \ll 1\right)$ denotes the current tracking error from $x$ to $z+$ terminal, while $\beta_{n}=1-\varepsilon_{n}$ and $\varepsilon_{n}\left(\left|\varepsilon_{n}\right| \ll 1\right)$ stands for the current tracking error from $x$ to $z$ - terminal of the MO-CCCII, respectively. Generally, these tracking factors remain constant and frequency independent in low to medium frequency ranges. The typical values of the non-ideal current transfer gains and the transconductance inaccuracy factor $\alpha, \beta_{p}$ and $\beta_{n}$, range from 0.9 to 1 , with an ideal value of 1 . However, at higher frequencies these tracking factors become frequency dependent. Given the non-idealities, currents generated from MO-CCCII can be defined as

$$
\begin{aligned}
I_{\text {out }}^{\prime}= & i_{z-}-i_{z+}=\left(\beta_{p}-\beta_{n}\right) \frac{\alpha v_{\text {in }}}{R_{\text {in }}}= \\
& \begin{cases}2 \beta_{p} \frac{\alpha v_{\text {in }}}{V_{T}} I_{B}=2 \beta_{p} q \frac{\alpha v_{\text {in }}}{k T} I_{B}, & v_{\text {in }}(t) \geq 0 \\
-2 \beta_{n} \frac{\alpha v_{\text {in }}}{V_{T}} I_{B}=-2 \beta_{n} q \frac{\alpha v_{\text {in }}}{k T} I_{B}, & v_{\text {in }}(t) \prec 0\end{cases}
\end{aligned}
$$

which results in an absolute error

$$
\text { Error }=\left|i_{\text {out }}-I_{\text {out }}^{\prime}\right| \text {. }
$$

The error (8) is a function of input voltage signals and varies depending on its contents. A way to express the error is to consider the values of the observed parameters as random quantities characterized by their PDFs (Probability Density Function). Therefore, the interval having a $2 \varepsilon$ width, around the nominal value of the observed parameters needs to be defined and associated with a certain distribution, eg uniform distribution.

From (7), the tracking errors slightly change the output current of the proposed full-wave circuits. However, the above relation does not include the error in determination of the interval in which the input voltage signal is negative (the ZCD error), which also defines the precision of the proposed rectification process. Figure 5 a shows the waveform of the output voltage in response to an input voltage step of $\pm 50 \mathrm{mV}$ for the proposed comparator. In Fig. 5b, the average delay times of the proposed comparator as a function of the input voltage amplitude is reported. As can be seen, at low input voltages, the response time of the proposed circuit is very small. As the input voltage is increased, the delay time are reduced, since the enhanced output voltage swing (due to the higher voltage values) cause $\mathrm{Q}_{19}$ and $\mathrm{Q}_{20}$ completely turn-off.

Simulation results confirm the fact that proposed ZCD circuits is capable of processing the input signal with a high precision. We suppose that the incremental sensitivities of the output current $i_{\text {out }}$ at parameters $\alpha, \beta_{p}, \beta_{n}$ and $T$ are: $1 ; 1 ; 1$ and -1 (all the active and passive sensitivities are of an equal unity in magnitude). Thus, the proposed circuit exhibits a low sensitivity performance.

The Monte Carlo approach [26] gives the lower and upper limits of interval which contains $95 \%$ of error samples. The Monte Carlo analysis in PSpice was used for simulations with a given error on different parameters and components (Monte Carlo predicts the behaviour of a circuit statistically when part values are varied within their tolerance range for 5\%), Fig. 6. This test is very useful for visualizing how the circuit will run with imperfect parameters as are used in reality. The number of individual simulation was 2000 . 
Table 2. PR200N and NP200N transistor parameters

NP200N

$. \mathrm{MODEL} N X 2 \mathrm{NPN} R B=262.5 \mathrm{IRB}=0 \mathrm{RBM}=12.5 \mathrm{RC}=25 \mathrm{RE}=0.5 \mathrm{IS}=242 \mathrm{E}-18 \mathrm{EG}=1.206 \mathrm{XTI}=2 \mathrm{XTB}=$ $1.538 \mathrm{BF}=137.5 \mathrm{IKF}=13.94 \mathrm{E}-3 \mathrm{NF}=1.0 \mathrm{VAF}=159.4 \mathrm{ISE}=72 \mathrm{E}-16 \mathrm{NE}=1.713 \mathrm{BR}=0.7258 \mathrm{IKR}=4.396 \mathrm{E}-$ $3 \mathrm{NR}=1.0 \mathrm{VAR}=10.73 \mathrm{ISC}=0 \mathrm{NC}=2+\mathrm{TF}=0.425 \mathrm{E}-9 \mathrm{TR}=0.425 \mathrm{E}-8 \mathrm{CJE}=0.428 \mathrm{E}-12 \mathrm{VJE}=0.5 \mathrm{MJE}=$ $0.28 \mathrm{CJC}=1.97 \mathrm{E}-13 \mathrm{VJC}=0.5 \mathrm{MJC}=0.3 \mathrm{XCJC}=0.065 \mathrm{CJS}=1.17 \mathrm{E}-12 \mathrm{VJS}=0.64 \mathrm{MJS}=0.4 \mathrm{FC}=0.5$

\section{PR200N}

$. \mathrm{MODEL} P X 2 \mathrm{PNP} R B=163.5 \mathrm{IRB}=0 \mathrm{RBM}=12.27 \mathrm{RC}=25 \mathrm{RE}=1.5 \mathrm{IS}=147 \mathrm{E}-18 \mathrm{EG}=1.206 \mathrm{XTI}=1.7 \mathrm{XTB}$ $=1.866 \mathrm{BF}=110.0 \mathrm{IKF}=4.718 \mathrm{E}-3 \mathrm{NF}=1 \mathrm{VAF}=51.8 \mathrm{ISE}=50.2 \mathrm{E}-16 \mathrm{NE}=1.65 \mathrm{BR}=0.4745 \mathrm{IKR}=12.96 \mathrm{E}-$ $3 \mathrm{NR}=1 \mathrm{VAR}=9.96 \mathrm{ISC}=0 \mathrm{NC}=2 \mathrm{TF}=0.610 \mathrm{E}-9 \mathrm{TR}=0.610 \mathrm{E}-8 \mathrm{CJE}=0.36 \mathrm{E}-12 \mathrm{VJE}=0.5 \mathrm{MJE}=$ $0.28 \mathrm{CJC}=0.328 \mathrm{E}-12 \mathrm{VJC}=0.8 \mathrm{MJC}=0.4 \mathrm{XCJC}=0.074 \mathrm{CJS}=1.39 \mathrm{E}-12 \mathrm{VJS}=0.55 \mathrm{MJS}=0.35 \mathrm{FC}=0.5$

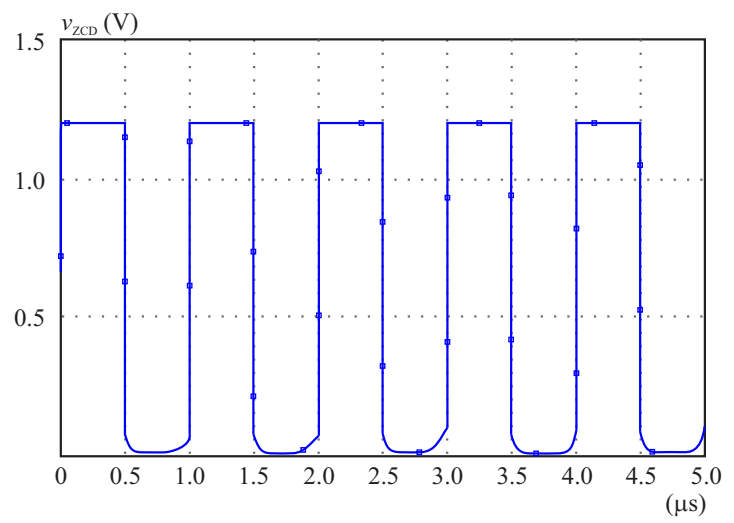

Fig. 7. Time-domain response of proposed ZCD

\section{Simulation results}

To confirm the given theoretical analysis, the proposed voltage-mode bipolar full-wave circuit in Fig. 1 was simulated using the PSpice program. The MO-CCCII and ZCD were realized by the schematic bipolar implementations given in Figs. 3 and 4, with the transistor model parameters of PR200N (PNP) and NP200N (NPN) of the bipolar arrays ALA400 from AT\&T [27], Tab. 2. The supply voltages and the values of the bias currents were $+V=-V=1.2 \mathrm{~V}$ and $I_{P}=300 \mu \mathrm{A}$ respectively, whereas the input voltage was within the range of $\pm 100 \mathrm{mV}$. Parameters of National Semiconductor bipolar circuits AH510 [28] were used as analogue current switch during simulation.

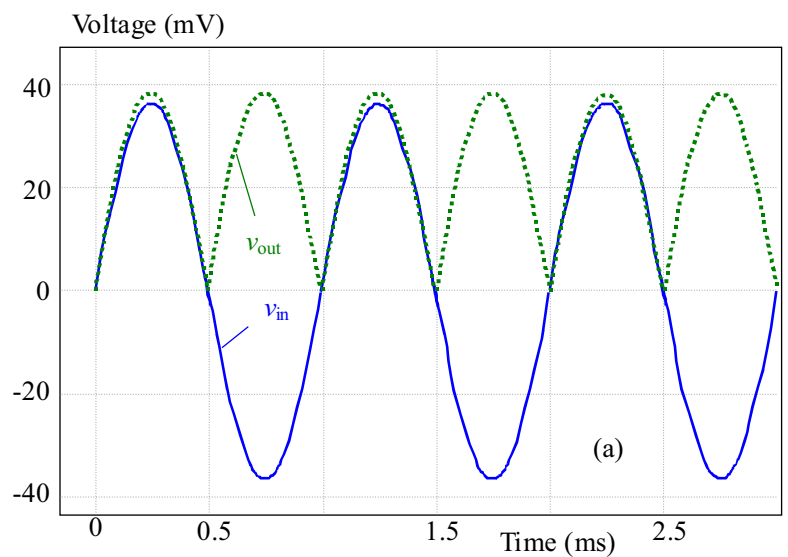

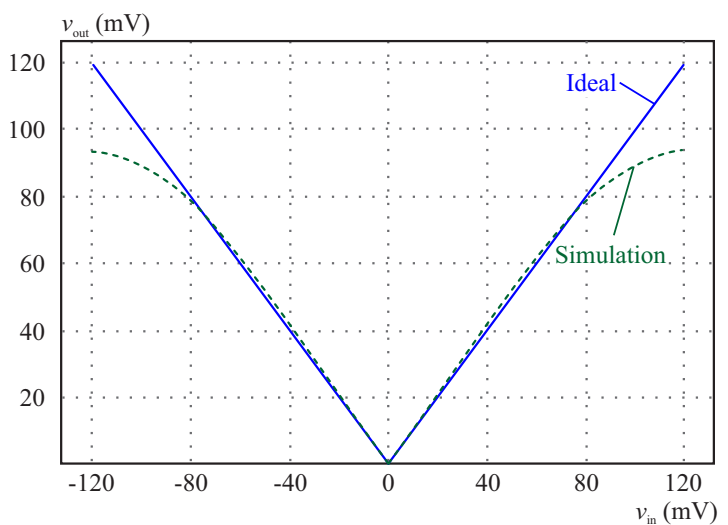

Fig. 8. DC transfer characteristics for the proposed rectifier circuit

Time response of the proposed ZCD circuits is shown in Fig. 7, where the input voltage signal was with $1 \mathrm{MHz}$ frequency and $20 \mathrm{mV}$ peak. Resistor $R_{1}=1 \mathrm{k} \Omega$ was used in the process of simulation. It is clear that the proposed solution detectors perform detection polarity of the input voltage signal in a very precise way, and the error that is due to imprecision in detection can be neglected in practical applications.

The DC characteristic of the proposed circuit for a frequency of $100 \mathrm{kHz}$ is shown in Fig. 8. Based on Fig. 8, it can be concluded that the proposed circuit retains a linear character in a wide voltage range.

Figure 9 shows the wave form of the signal at the output of the circuit shown in Fig. 1 (voltage $v_{\text {out }}$ ), at different frequencies. For these simulations, the input signal

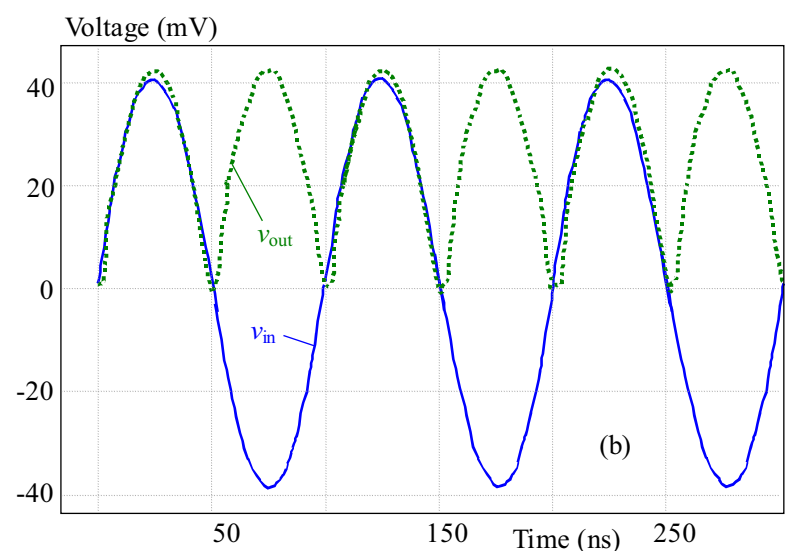

Fig. 9. Time-domain response of the proposed full-wave rectifier for different frequencies of (a) — $1 \mathrm{kHz}$ and (b) - $10 \mathrm{MHz}$ 


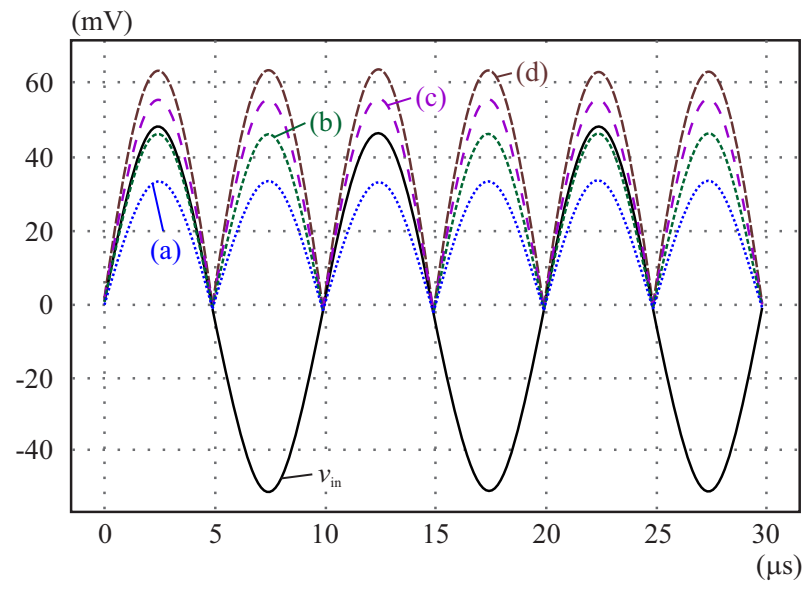

Fig. 10. Tunability of the gain of the proposed rectifier with changing the bias current $I_{B}(\mathrm{a})-I_{B}=200 \mu \mathrm{A},(\mathrm{b})-I_{B}=130 \mu \mathrm{A}$, (c) $-I_{B}=115 \mu \mathrm{A},(\mathrm{d})-I_{B}=100 \mu \mathrm{A}$

is taken as a sinusoidal voltage signal with $40 \mathrm{mV}$ peak value and different frequencies of $1 \mathrm{kHz}$ and $10 \mathrm{MHz}$ are selected. Figure 9 shows that the output waveform of the proposed rectifier is in a good agreement with the theoretical ones at low and high frequencies. However, with the increased frequency of the processed signal, the deviations are increased as well.

The total power dissipation was $2.83 \mathrm{~mW}$. Small power consumption of the proposed circuits occurs due to the application of low-voltage current mode and transconductance mode integrated circuits, along with the use of bipolar transistor technique. Applying the current mode signal processing to solve the issues under consideration is a sensible approach to the problem. However, similar and sometimes lower power consumption can be achieved using CMOS technology instead of the bipolar one.

To test the tunability of the gain of the proposed rectifier circuit, the bias current of the MO-CCCI $\left(I_{B}\right)$ is changed and the results are shown in Fig. 10. For these simulations, the input signal is taken as a sinusoidal voltage signal with $100 \mathrm{kHz}$ frequency and $50 \mathrm{mV}$ peak value, while the load was $R_{L}=100 \Omega$.

\section{Harmonic Distortion}

A further indication of the performance of each of the full-wave rectifiers can be gleaned by examining the distortion already present in a full-wave rectified signal. When a sinusoidal signal of frequency $f$ is applied to a full-wave rectifier, the steady-state response at the output ideally consists of harmonic components at $2 f, 4 f$, $6 f$, etc. The harmonics in the signal causes the distortion in the output of the circuit. Because of its periodic nature, these harmonic components can be analyzed by the Fourier series. The magnitude of each harmonic of a waveform as shown in Fig. 11 is obtained with fast Fourier transform using PSpice.

The total harmonic distortion, or THD, of a signal is a measurement of the harmonic distortion present and is defined as the ratio of the sum of the powers of all

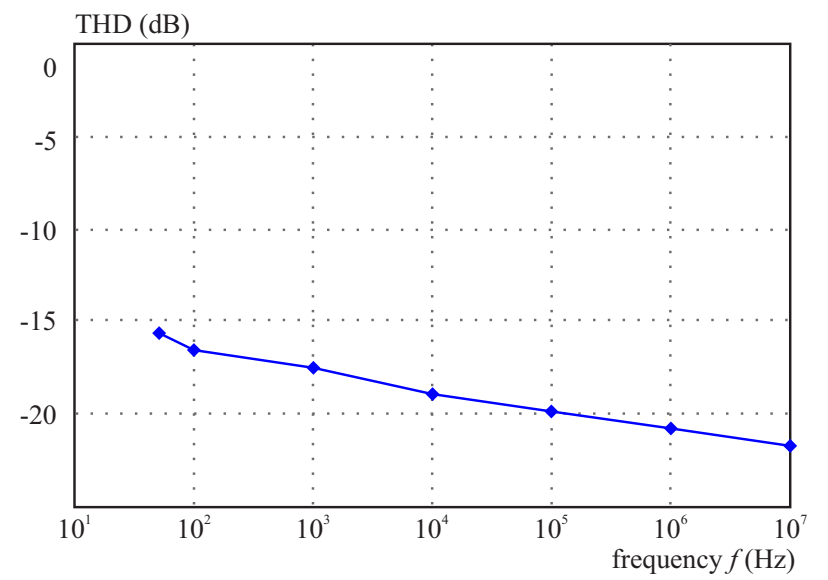

Fig. 11. Total harmonic distortion (THD) versus frequency at input amplitude voltage of $50 \mathrm{mV}$

harmonic components to the power of the fundamental frequency

$$
T H D(\mathrm{~dB})=20 \log \left(V_{T H D}\right), V_{T H D}=\sqrt{\frac{\sum_{n=2}^{N} V_{n}^{2}}{V_{1}^{2}}}
$$

where $V_{1}$ is the fundamental frequency voltage content, $V_{n}$ is $n$th the harmonic voltage content, and $n=$ $2,3,4, \ldots$ In the case of a full-wave rectifier, the steadystate response at the output consists of even harmonics.

Figure 11 shows the total harmonic distortion of the output voltage of the proposed circuit, Fig. 1. The THD of the proposed circuit is $-15.6 \mathrm{~dB}$ at $50 \mathrm{~Hz}$ and $-20.8 \mathrm{~dB}$ at $1 \mathrm{MHz}$ with an input signal of $50 \mathrm{mV}$. The THD is significantly lower than in $[2,29,30]$ (the THD of previously reported circuit slowly increases with frequency), because for higher frequency ranges, the switching $\mathrm{ON}$ and $\mathrm{OFF}$ of diodes becomes sluggish due to its higher impendence and more distortions.

\section{Conclusions}

In this paper, new full-wave rectifier topologies are given. The circuit employs only two active component and one resistor which is advantageous from the integration point of view and operates in VM. The workability of the proposed circuits is demonstrated by PSpice simulations using the bipolar arrays ALA400 from AT\&T technology parameters. The effects of the non-idealities of the active elements are also investigated. The proposed circuit has a high precision, low power consumption and wide bandwidth.

\section{Acknowledgments}

This work was supported by Ministry of Education and Science of the Republic of Serbia within the projects 42009 and OI-172057. 


\section{REFERENCES}

[1] R. B. Northrop, Analog Electronics Circuits, Reading, MA, Addison- Wesley, 1990.

[2] P. B. Petrovic, "A New Tunable Current-Mode Peak Detector", Microelectronics Journal, 2014, vol. 45, no. 6, 805-814.

[3] P. B. Petrovic, "A New Peak Detector Based on Usage of CCCIIs", Proceedings of Advances in Instrumentation and Sensors Interoperability, 19th IMEKO TC 4 Symposium and 17th IWADC Workshop, July 18-19 2013, Barcelona, Spain.

[4] A. Fabre, O. Saaid, F. Wiest and C. Bouchheron, "Current Controllable Bandpass Filter Based on Translinear Conveyors", Electron. Lett., 1995, vol. 31, 1727-1728.

[5] S. J. Gift, "A High-Performance Full-Wave Rectifier Circuit" Int. J. Electron., 2000, vol. 87, no. 8, 925-930.

[6] J. R. Angulo, R. G. Carvajal, J. M. Hereida and A. Torrabla, "Very Low-Voltage Class AB CMOS Precision Voltage and Current Rectifier", Proceedings of IEEE Intern. Sym. on Cir. and Sys., 2000, III-5-III-8.

[7] A. V. Garcia, R. Venkatasubramanian, J. S. Martinez and E. S. Sinencio, "A Broadband CMOS Amplitude Detector for On-Chip RF Measurements", IEEE Trans. Instrum. Meas., 2008, vol. 57, no. 7, 1470-1477.

[8] C. Peters, J. Handwerker, D. Maurath and Y. Manoli, "A Sub-500mV Highly Efficient Active Rectifier for Energy Harvesting Applications", IEEE Trans. Cir. Sys.-I, 2011, vol. 58, no. $7,1542-1550$.

[9] S. Maheshwari, "Current Controlled Precision Rectifier Circuits", Journal of Circuits, Systems, and Computers, 2007, vol. 16 , no. 1, 129-138.

[10] A. A. Khan, M. A. El-ela, M. A. Al-Turaigi, "Current-Mode Precision Rectification", Int. J. Electron., 1995, vol. 79, no. 6, $853-859$.

[11] B. Wilson and V. Mannama, "Current-Mode Rectifier with Improved Precision", Electronics Letters., 1995, vol. 31, no. 4, $247-248$.

[12] E. Yuce, S. Minaei and O. Çicekoglu, "Full-Wave Rectifier Realization using only two CCII+s and NMOS Transistors", Int. J. Electron., 2006, vol. 93, no. 8, 533-541.

[13] S. Minaei and E. Yuce, "A New Full-Wave Rectifier Circuit Employing Single Dual-X Current Conveyor", Int. J. Electron., 2008, vol. 95, no. 8, 777-784.

[14] F. J. Lidgey, K. Hayateh and C. Toumazou, "New Current-Mode Precision Rectifiers", Proc. IEEE Int. Symp. Circuits and Systems, Chicago, USA, 1993, 1322-1325.

[15] C. Toumayou, F. J. Lidgey and S. Chattong, "High Frequency Current Conveyor Precision Full-Wave Rectifier", Electron. Lett., 1994, vol. 30, no. 10, 745-746.

[16] J. Koton, N. Herencsar and K. Vrba, "Minimal Configuration Precision Full-Wave Rectifier using Current and Voltage Conveyors", IEICE Electron. Express, 2010, 844-849.

[17] J. Koton, N. Herencsar and K. Vrba, "Current and Voltage Conveyors in Current and Voltage-Mode Precision Full-Wave Rectifiers", Radioengineering, 2011, vol. 20, no. 1, 19-24.

[18] J. Koton, N. Herencsar, K. Vrba and S. Minaei, "Precision Full-Wave Current-Mode Rectifier using Current Differencing
Transconductance Amplifier", Proc. of 2011 Int. Conf. on Computer and Communication Devices (ICCCD 2011), Bali Island, Indonesia, 1-3 April 2011, 71-74.

[19] S. Hashemi, M. Sawan and Y. Savaria, "A Novel Low-Drop CMOS Active Rectifier for RF-Powered Devices: Experimental Results", Microelectron. Journal, 2009, vol. 40, no. 11, 1547-1554.

20] C. Jongkunstidchai, C. Fongsamut, K. Kumawachara and W. Surakampontorn, "Full-Wave Rectifiers based on Operational Transconductance Amplifiers", AEU Int. J. Electron. Commun., 2007, vol. 61, no. 3, 195-201.

[21] M. Kumngern, "CMOS Current-Mode Precision Full-Wave Rectifier with Improved Bandwidth", 2012 Second Int. Conf. on Digital Information and Communication Technology and its Applications (DICTAP), 2012, 283-286.

[22] F. Khateb, J. Vavra and D. Biolek, "A Novel Current-Mode Full-Wave Rectifier based on One CDTA and Two Diodes", Radioengineering, 2010, vol. 19, no. 3, 437-445.

[23] J. Koton, N. Herencsar and K. Vrba, "Current-Mode Precision Full-Wave Rectifier using Single DXCCII and Two Diodes", 20th European Conf. Circuit Theory and Design (ECCTD), 2011.

Received 29 March 2016

Predrag B. Petrović was born in Čačak, Yugoslavia, on January 26, 1967. He received the B.S.E.E. and MS degrees in electrical engineering from the University of Belgrade Yugoslavia, in 1991 and 1994, respectively, and PhD degree in the field of digital signal processing at the University of Novi Sad in 2004. His main interest is digital signal processing, microcontroller programming, power electronics, AD conversion, mathematics, and cryptology. He published more then 150 journals and conference papers, five university books, one international monograph and holds five patents. He is the member of IEEE, IEICE and MENSA.

Milan Vesković was born in Kraljevo in 1969. Hi studied electrical engineering at the Faculty of Technical Sciences in Novi Sad, Serbia, receiving the BSc Degree in 2002, and MSc degree in 2009 at the Technical faculty in Čačak, where he is currently working toward the $\mathrm{PhD}$ degree. Major field of study are electromagnetic and electronics. He is author and co-author of more scientific journal papers and conference reports.

Slobodan R. Đukić was born in Cikote, Serbia, in 1950. He studied electrical engineering at the Electrotechnical Faculty, University of Belgrade, Serbia, receiving the BSc degree in 1974. and MSc degree in 1993. He received the PhD degree in Electronics at Technical Faculty Čačak, Serbia, in 1999. Major field of study is Electronics. He is author and co-author of many scientific journal papers and conference reports. His research interest is current mode processing circuits. Also, his research interests are soft magnetic materials and sensors. 